\title{
IMAGENS DO ESCRITOR E DO POETA \\ em Memórias do subdesenvolvimento e Terra em transe
}

\author{
Jair Tadeu da Fonseca \\ UFMG
}

\begin{abstract}
RESU MO
Este artigo é um estudo comparado entre Terra em Transe, de Glauber Rocha, e Memórias do subdesenvolvimento, de Gutiérrez Alea. Seu objetivo é discutir os significados das figuras do poeta e do escritor em ambos os filmes, considerando seus papéis nas cenas cultural, social e política latino-americana.
\end{abstract}

\section{PALAVRAS-CHAVE}

Glauber Rocha, Gutiérrez Alea, cinema, literatura, cultura latino-americana

No livro Brasil em tempo de cinema (1976), trabalho pioneiro sobre o Cinema Novo, escrito entre 1965 e 1966, Jean-Claude Bernardet encara o movimento como mais uma manifestação artística da classe média, que, segundo ele, seria a grande responsável pela movimentação cultural no país. O enfoque sociológico desse trabalho, se algo restritivo, não é desprovido de nuances e de uma cuidadosa observação das películas abordadas, trazendo uma perspectiva que muito revela sobre as relações entre certos tipos de filmes realizados no período abordado pelo crítico, de 1958 a 1966, e a sociedade. Filmes que retratam o popular pelo viés da marginalidade são relacionados ao relativo marginalismo dos artistas de classe média que realizavam tal cinema. Ao analisar Deus e o Diabo na Terra do Sol (1965), de Glauber Rocha, Bernardet escreve:

Assim, reencontramos em Antônio das Mortes aquilo que vimos na análise de $\mathrm{A}$ grande feira: a estrutura da situação social da classe média, tratando-se, desta vez, nitidamente de sua parte progressista. Ligada às classes dirigentes pelo dinheiro que estas lhe fornecem, pretende colocar-se na perspectiva do povo. Essa situação, sem perspectiva própria, faz com que ela não consiga constituir-se realmente em classe, mas seja atomizada. E Antônio das Mortes tem essa má consciência de que fala Marx. Essa má consciência não é outra que a de Glauber Rocha, que a minha, que a de todos nós, ou melhor, de cada um de nós. E é por isso, parece-me, que Antônio das Mortes tem tamanho poder de sedução, e por isso resiste tanto à interpretação. Porque interpretar Antônio é nos analisarmos a nós próprios. ${ }^{1}$

A idéia de que a intelectualidade artística de classe média possa ser traduzida alegoricamente em uma figura como a de Antônio das Mortes, ousada para a época em que o ensaio de Bernardet foi escrito, embora não aceita de todo por Glauber, torna-se ainda mais pertinente quando o cineasta realiza Terra em transe (1967), mostrando os impasses e as vacilações do poeta-político Paulo Martins, e quando filma $O$ dragão da maldade contra o santo guerreiro (1969), retomando a ambígua personagem do matador de cangaceiros.

${ }^{1}$ Bernardet. Brasil em tempo de cinema, p.82. 
Em um trabalho mais recente, Historiografia clássica do cinema brasileiro, de 1995, Bernardet aborda, sob uma ótica menos sociológica, a figura do intelectual no cinema brasileiro, geralmente um poeta ou escritor, sempre um homem de palavras, que nos filmes é uma metáfora do próprio cineasta. Referindo-se principalmente a O desafio (Paulo César Saraceni, 1965), Terra em transe e Os inconfidentes (Joaquim Pedro de Andrade, 1972), o crítico escreve:

Todos esses filmes são dolorosos, com matizes às vezes masoquistas, obras de intelectuais que perderam seu papel social e não encontraram outro. Seus autores falam em geral da intelectualidade de esquerda, ou que se dizia tal, ou dessa esquerda que passou a ser qualificada de "festiva", mas falam também de si mesmos e do grupo a que pertencem, donde as conotações masoquistas. Os personagens representantes da intelectualidade brasileira derrotada são também metáforas dos próprios cineastas: estes questionam, por meio de suas personagens, a situação e o papel do cinema e dos cineastas. ${ }^{2}$

Após o golpe militar de 1964, vários cineastas incluem em seus filmes o tratamento de seus próprios impasses, perdidas as esperanças de uma transformação político-social mais imediata, o que os obriga a rever sua participação nessas tentativas fracassadas de transformação e a encarar um futuro pouco promissor. É significativo que as figuras que representam os intelectuais de esquerda às voltas com a política e suas desilusões sejam quase sempre escritores e poetas, mas isso, em vez de reforçar a aura da literatura, mostra que ela é incapaz de satisfazer o intelectual amargurado.

Os personagens literatos mantêm relações conflituosas com o literário $(O$ desafio, Terra em transe), ou são alvo de uma ironia feroz (Os inconfidentes). A literatura, o literário, a escrita estão sob suspeita. Não funcionam bem no corpo social, o que produzem é questionado até pelos próprios poetas. (...)

Além do mais, a literatura é suspeita, mas até certo ponto, pois em momento algum se questiona a construção de personagens e de metáforas da intelectualidade a partir dela. A literatura é questionada na diegese, não como matéria-prima para a elaboração do filme. ${ }^{3}$

A literatura é suspeita no plano da diegese porque está, como metáfora, no lugar do cinema, que também se mostra uma arma ineficaz de combate político, quando se está derrotado e as condições de atuação política e de criação artística são adversas. Entretanto, como observa Bernardet, isso não impede que haja, nesse caso, certa correspondência entre recursos literários e fílmicos. Aliás, essa correspondência revela que os filmes não são uma mera crítica aos limites da cultura letrada, nem são, simplesmente, películas sobre os escritores e os poetas, mas se mostram como produções fílmicas de cineastas cuja formação literária transparece em seu trabalho com a linguagem cinematográfica, o que não impede a crítica dessa formação, ou seja, uma autocrítica. No ano de lançamento de Terra em transe, 1967, Glauber escreve "Tricontinental”, texto em que homenageia Che Guevara, recentemente assassinado:

Até 1964, abril, queda de Goulart, a maioria dos intelectuais brasileiros acreditava na "revolução pela palavra".

${ }^{2}$ BernaRdet. Historiografia clássica do cinema brasileiro, p.152.

${ }^{3}$ Bernardet. Historiografia clássica do cinema brasileiro, p.156. 
A vanguarda política latino-americana é sempre desencadeada por intelectuais e aqui, com muita freqüência, os poemas precedem os fuzis. ${ }^{4}$

A descrença no poder da palavra acentua-se com a derrota de 1964, o que se traduz em Terra em transe no desejo expresso do verborrágico poeta-político Paulo Martins de abandonar a poesia: "A poesia não tem sentido... Palavras... As palavras são inúteis". Ao partir para a ação, o poeta-político encontra a morte, pois ela faz parte do jogo, é um risco a correr, e seu ato, ou atuação, tornando sua poesia em política, faz desta, de volta, uma atividade poética. Glauber termina "Tricontinental" fazendo sua profissão de fé: "No momento em que a mise-en-mort de Chê se faz legenda é impossível negar, Tricontinental, que a poesia é uma práxis revolucionária”. ${ }^{6}$ Não é difícil relacionar a morte de Paulo à de Guevara, mas note-se que esta ocorreu depois do lançamento de Terra em transe, que também antecipa, alegoricamente, a luta armada no Brasil e no restante da América Latina, seu desesperado isolamento, derrota e destruição.

À mesma época em que o filme de Glauber começava a ser exibido, realizava-se em Cuba uma película sobre a crise de um outro tipo de intelectual latino-americano, Memórias do subdesenvolvimento (1968), de Gutiérrez Alea, capaz de revelar um diferente ponto de vista crítico e estético sobre essa figura em crise, a qual quer passar ao largo, como se isso fosse possível, de uma sociedade que atravessa um processo revolucionário. O filme baseia-se no romance homônimo do escritor cubano Edmundo Desnoes, publicado em Cuba, em 1962, e que depois da feitura da película foi não apenas traduzido para o inglês, por seu autor, mas reescrito, tendo em vista sua adaptação para o cinema. Publicado nos Estados Unidos pela primeira vez em 1967, o livro constitui um caso praticamente inédito: o autor do romance original, que colaborou com o diretor na escrita do roteiro, incorporou várias das passagens deste ao livro, cujo título em inglês, Inconsolable memories, é uma citação de Hiroshima, meu amor (1959), de Alain Resnais, com roteiro de Marguerite Duras. O filme francês ressoa em Memórias do subdesenvolvimento tanto em função do entrelaçamento da memória individual e da coletiva, tema de ambas as películas, quanto por causa do horror atômico, com que termina a Segunda Grande Guerra Mundial, no caso de Hiroshima, e com que se desenrola a guerra fria, no caso de Memórias.

O filme de Alea, mostra a história de Sergio Carmona, ex-homem de negócios, cuja família rica abandona Cuba, algum tempo após a revolução, deixando-o em Havana, solitário mas aliviado por livrar-se dos pais e da esposa, que não suporta. Tendo se recusado a partir, ele vive da renda proporcionada por alguns dos bens familiares expropriados pelo governo. Ou seja, ele não trabalha, é incapaz de agir, nada fazendo além de tentar seduzir mulheres belas e escrever suas memórias.

De fato, não consegue escrever plenamente, pois tem apenas veleidades literárias, mas conhecemos suas "memórias" através das observações, feitas com sua voz off, que tece sobre seu passado e sobre a realidade "subdesenvolvida" que o cerca, à qual observa à distância, como se ele não fizesse parte dessa realidade do subdesenvolvimento, até notar que está enredado nela. Aos poucos, Sergio percebe que sua suposta superioridade intelectual não lhe permite escapar disso e, após assistir a uma Mesa-redonda sobre

${ }^{4}$ Rocha. Revolução do Cinema Novo, p.75.

${ }^{5}$ Rocha. Roteiros do Terceyro Mundo, p.301.

${ }^{6}$ Rocha. Revolução do Cinema Novo, p.78. 
Literatura e Subdesenvolvimento - em que vemos escritores de verdade, entre eles o autor da história filmada - , o protagonista sai para as ruas e ouvimo-lo expressar sua descrença no verbo, como Paulo Martins:

As palavras devoram as palavras e deixam você nas nuvens ou na lua. A mil milhas de distância. Como pode alguém livrar-se do subdesenvolvimento? Ele marca tudo. Tudo. (...) Você está só. No subdesenvolvimento nada tem continuidade, tudo é esquecido. As pessoas não são consistentes. Mas você se lembra de muitas coisas, você lembra demais. Onde estão sua família, seu trabalho, sua mulher? Você não é nada, você está morto. Agora começa, Sergio, sua destruição final. ${ }^{7}$

O que resta a Sergio, sem a classe social de que fazia parte, são as memórias, que, mais do que reconstituir seu passado, traduzem-se nos signos de sua desconstrução no presente das lembranças, que se chocam às percepções do momento atual. Ao compararmos Terra em transe a Memórias do subdesenvolvimento, considerando as duas situações sociopolíticas diferentes em que se baseiam, temos duas configurações, semelhantes em certos aspectos, de dois tipos diversos de literatos, desiludidos com a palavra e com seu próprio papel social. Paulo Martins é um político que luta para se livrar de seus laços e compromissos com o poder burguês, mas só o consegue fracassando como revolucionário, para que, como poeta, possa cantar "o triunfo da beleza e da justiça". Sergio Carmona apresenta apenas ligações indiretas com a política de sua terra, que aparentemente pouco lhe interessa, e "livra-se" de seus laços e compromissos burgueses, apesar de nada ter feito para isso, graças à revolução — o que lhe permite ficar às voltas com suas "memórias inconsoláveis".

A crise de ambos os literatos memoriosos passa pela reconstituição de suas vidas no presente de sua destruição. Ao morrer, baleado por ter resistido a um golpe militar em Eldorado, Paulo, como um solista de ópera, entoa o canto despedaçado de si mesmo e de sua terra, enquanto se imprime na tela um trecho de um poema de Mário Faustino, "Balada (Em memória de um poeta suicida)". Sergio narra suas memórias, que também envolvem acontecimentos sociais e políticos, esperando pela sua morte, em meio à matança coletiva que poderia advir da chamada Crise dos Mísseis, quando Cuba correu o risco de ser destruída por armas atômicas, caso houvesse ataque norte-americano, em outubro de 1962. É importante notar que no roteiro original de Memórias consta que o filme terminaria com o suicídio de Sergio, em vez de ter o final aberto de sua angustiada espera pelos acontecimentos, o qual prevaleceu. ${ }^{8}$ Entretanto, em ambos os casos, temos o que poderíamos chamar de "suicídio de classe", alegorizado pelos protagonistas.

Ao considerar os textos do chamado Terceiro Mundo como "alegorias nacionais", em contraposição ao que ocorre na cultura capitalista do chamado Primeiro Mundo, na qual "há um divórcio radical entre o privado e o público, entre o poético e o político", Fredric Jameson afirma:

Os textos do Terceiro Mundo, mesmo os que aparentemente são privados e investidos de uma dinâmica propriamente libidinal — necessariamente projetam

\footnotetext{
${ }^{7}$ Alea, Desnoes. Memories of underdevelopment, p.77. (Todas as citações de textos cujas referências são dadas em língua estrangeira foram traduzidas pelo autor deste artigo.)

${ }^{8}$ Cf. Alea, Desnoes. Memories of underdevelopment, p.110.
} 
uma dimensão política na forma da alegoria nacional: a história [story] do destino individual privado é sempre uma alegoria da aguerrida situação da cultura e da sociedade públicas do Terceiro Mundo. ${ }^{9}$

A generalização feita por Jameson de que todos os textos do Terceiro Mundo seriam alegorias nacionais foi criticada por Aijaz Ahmad, que, pela contestação da própria categoria de Terceiro Mundo, a qual desconheceria a heterogeneidade das partes do mundo às quais corresponderia, também põe em questão "a 'alegoria nacional' como seu metatexto, bem como marca de sua constituição e diferença”. ${ }^{10}$

Se considerarmos os filmes em questão, a dimensão privada teria mesmo um alcance público por força da alegoria, que, entretanto, no caso de Glauber, não é apenas nacional, mas latino-americana, e no de ambos os cineastas, trata-se especificamente da alegorização do papel do artista-intelectual em relação ao seu povo e às lutas políticas com as quais vê-se envolvido, direta ou indiretamente. Ou seja, temos também uma alegoria de classe, em que o artista-intelectual é transfigurado nela de modo que sejam esmaecidos os traços que seriam individualmente biográficos, pessoais e subjetivos, servindo essa figura alegórica, de caráter exemplar, também como mediador imaginário entre o escritor-cineasta, o grupo social a que pertence e os demais setores da sociedade que sua obra figura ou transfigura.

Para que seja tratada a questão definida dialeticamente pelo diretor de Memórias do subdesenvolvimento como "o confronto entre o indivíduo e a sociedade, entre a consciência individual e as circunstâncias históricas que a condicionam de uma maneira ou de outra", ${ }^{11}$ confrontam-se também os pontos de vista do protagonista, subjetivos, e o da câmera, objetivo, que nem sempre coincide com o da personagem, também um objeto da película, mas que se chocam e se mesclam na composição do filme como um todo.

As memórias do intelectual em crise são as memórias do subdesenvolvimento de seu país, e o transe do poeta-político corresponde ao transe de sua terra em crise, em virtude do redimensionamento alegórico instaurado nos filmes ser capaz de desdobrar o particular em geral, o privado em público, e vice-versa. Tudo isso já está indicado pela prosopopéia, ou personificação alegórica, que caracteriza os títulos dos dois filmes. Em ambos, o recurso às memórias e ao transe da rememoração reconstitui e desconstrói as "vidas" de seus protagonistas em um cenário mais vasto, ao qual se conferem corpo, rosto, voz e memória. Constitui-se o universo criado pelos filmes nesse jogo entre reconstituição e desconstrução, através do qual os cineastas colocam em xeque seu próprio papel social, pondo em cena não os firmes revolucionários que lideram a luta do povo, mas os intelectuais ambíguos, vacilantes e deslocados por sua situação de classe e seus conflitos pessoais.

Ao analisar Memórias do subdesenvolvimento, Julianne Burton vê nele uma "múltipla ironia", dada a escolha do "tema do papel do intelectual burguês na nascente sociedade revolucionária”, feita pelo diretor Alea e pelo escritor Desnoes:

A complexa e compreensiva caracterização que vão fazendo do protagonista, enquanto ambos tentam dar-lhe vida na tela, deriva de sua própria experiência e é,

\footnotetext{
${ }^{9}$ JAMESON. Third-World Literature in the Era of Multinational Capitalism. Social text, p.69.

${ }^{10}$ AhmAD. In theory: classes, nations, literatures, p.105.

${ }^{11}$ Alea. Memórias de Memórias. In: Alea. Dialética do espectador, p.108.
} 
em si mesma, uma expressão de seus esforços pessoais para vencer a síndrome que Sergio, em definitivo, não poderá superar. ${ }^{12}$

No caso de Terra em transe, também é possível associar a personagem de Paulo Martins, cineasta, jornalista e poeta, às voltas com a política de sua terra conturbada por um golpe militar, à do próprio Glauber, mas tanto seu filme quanto Memórias, compreendidos como alegorias, podem ser entendidos como "biografias épicas", para usar a definição que Jorge de Lima fez de sua Invenção de Orfeu, ou como prosopopéicas biografias de classe. Ou, mais precisamente, como biografias de uma atomização de classe. Em Terra em transe e Memórias do subdesenvolvimento, no vácuo ou na pletora da revolução, o lugar - e a falta de lugar — dos artistas-intelectuais permitem a (auto)crítica exemplar de seu elitismo e sua solidão.

O filme cubano mostra Sergio, da sacada de seu belo apartamento, observando Havana com um telescópio: "A luneta no terraço é o símbolo mais contundente de sua atitude perante a realidade: ele vê tudo de cima e de longe, é capaz de julgar a realidade a partir de seu ponto de vista subjetivo — , mas não pode participar nela ativamente". ${ }^{13}$ Alea considera o telescópio como signo do papel de espectador passivo que o protagonista assume frente à grave situação de seu país, enquanto outro crítico considera a luneta um indefectível símbolo fálico, com o qual Sérgio trataria de "penetrar a realidade", pois "sua única maneira de relacionar-se com os demais - pelo menos, de tentá-lo - é através da observação e do sexo". ${ }^{14}$ Do nosso ponto de vista, o telescópio pode ser também uma metáfora da tarefa intelectual, de sua fria e curiosa aproximação dos objetos, a qual, sendo supostamente mais racional e científica, na verdade revela um afastamento, uma alienação.

De todo modo, podemos considerar o instrumento ótico como metáfora da câmera, que permite ver mais, e de outra forma, sendo que a amplitude com que aspectos da realidade podem ser selecionados e apreendidos serve já à sua futura manipulação. Outro dado do filme possibilita ir além da clássica figura que batuca em sua máquina de escrever e permite tomar o escritor como metáfora do cineasta: um dos meios utilizados por Sergio para registrar parte do material utilizado em suas memórias é um gravador. Através dele temos oflashback de sua conturbada vida conjugal, em que se percebe, como subtexto, a conturbação política, social e econômica que sacode o país. Além disso, é evidente o modo como o protagonista provoca a mulher, em uma discussão gravada, de maneira a "fazer cena", como se a dirigisse.

Prossegue o binômio escritor-cineasta em outro momento do filme, no qual Sergio procura um amigo, que é diretor de cinema, como parte de um plano para seduzir uma garota, Elena, que deseja ser atriz, segundo explica, porque está cansada de ser ela mesma e assim pode tornar-se outra pessoa, sem que pensem que ela está louca. Sergio argumenta que o trabalho de atores e atrizes não se pauta apenas pela mudança e sim pela repetição, ao mesmo tempo em que vemos uma seqüência de clips de cenas eróticas de filmes diversos, sendo que cada uma é repetida rítmica e rapidamente. Na seqüência seguinte, mostramse as personagens em uma sala do ICAIC (Instituto Cubano de Arte e Indústria

\footnotetext{
${ }^{12}$ Burton. Memorias del subdesarrollo en tierras del superdesarrollo. In: Fornet (Org.). Alea: Una retrospectiva crítica, p.94.

${ }^{13}$ Alea. Memórias de Memórias. In: Alea. Dialética do espectador, p.106.

${ }^{14}$ Fernández. In: Fornet (Org.). Alea: una retrospectiva crítica, p.107-8.
} 
Cinematográficas), acabando de assistir aos clips eróticos. O cineasta "amigo" de Sergio é "representado" por Gutiérrez Alea, que lhe explica que aqueles trechos de filmes, cortados pela censura do governo de Fulgencio Batista, destronado pela revolução, serão utilizados, em uma colagem, na feitura de uma nova película, que não seria censurada...

A mise en abîme encontrada em Memórias também está presente, sob outras formas, em Terra em transe, em que o literato desdobra-se igualmente em cineasta, como na cena em que Paulo Martins abre uma janela e com uma câmera — outro aparelho ótico — tira uma fotografia, exatamente quando ouvimos os versos: "Todas as piadas são possíveis na tragédia de cada dia. / Eu, por exemplo, me dou ao vão exercício da poesia". ${ }^{15}$ Além de poeta e jornalista, Paulo é cineasta, pois realiza o filme "Biografia de um aventureiro", que vemos dentro de Terra em transe, apresentado como reportagem na TV Eldorado, com o objetivo de atacar seu ex-amigo, o político reacionário, corrupto e oportunista Diaz. Além disso, como em Memórias, no filme de Glauber cenas de documentário são enxertadas em seqüências ficcionais. Em Terra em transe, nas seqüências dos comícios do líder populista Vieira, candidato a governador da província de Alecrim, podem ser identificadas cenas de Maranhão 66, documentário de curta-metragem feito por Glauber sobre a posse de José Sarney como governador de seu estado. $\mathrm{O}$ dinheiro ganho com a feitura do curta viria a ser utilizado na produção de Terra em transe, tendo a experiência servido ainda como "laboratório" de algumas das situações criadas no filme. A incorporação de um clip de Maranhão 66, documentário sombrio e nada laudatório, a um filme político de ficção, também sombrio, duplica ironicamente a situação política e social do país e a própria condição do autor, que "representa", fora das telas, o dilacerante papel de Paulo Martins em seu mundo de irrisão.

Em Memórias do subdesenvolvimento e Terra em Transe, a auto-reflexividade e a "história-dentro-da-história" permitem tratar a relação entre ficção e realidade de modo a considerarmos metaforicamente a fita de cinema como uma fita de Möbius, que só tem um lado, no qual o "dentro" e o "fora" se encontram, se chocam e se interpenetram. No filme cubano, quando Sergio percebe que está indiretamente envolvido na luta política de sua terra, são mostradas cenas de documentários sobre a prisão e o julgamento dos mercenários treinados pela CIA, vindos de Miami, que haviam caído prisioneiros na malfadada tentativa de invasão de Cuba através de Playa Girón, ou Baía dos Porcos, em 1961. Quando essa seqüência do filme começa, com imagens dos mercenários presos caminhando por uma estrada, surge uma frase sobreposta: "a verdade do grupo está no assassino"; vários deles, os chefes, são da classe social de Sergio, em cuja "divisão social e moral do trabalho" desempenham vários papéis: são "o sacerdote, o homem da livre empresa, o diletante oficial, o torturador, o filósofo, o político e inúmeros filhos de boa família", conforme ouvimos pela voz do protagonista, enquanto imagens de documentários são mostradas, sendo que todos os acusados, em seus depoimentos, negam que sejam responsáveis pela ação e por outros crimes de tortura, assassinato e terrorismo perpetrados contra a revolução. ${ }^{16}$ Explica-se a fala de Sergio, que, sabemos, não é um revolucionário, pela leitura que faz de Moral burguesa y revolución, um livro de León Rozitchner.

Às imagens dos depoimentos dos acusados e de algumas de suas vítimas, intercalamse cenas de festas da alta sociedade cubana à época do governo de Fulgencio Batista,

\footnotetext{
${ }^{15}$ Rocha. Roteiros do Terceyro Mundo, p.302.

${ }^{16}$ Alea, Desnoes. Memories of underdevelopment, p.44-7.
} 
enquanto se ouve a voz de Sergio comentar: "Na divisão do trabalho moral, o matador de aluguel permite a existência dos que não estão diretamente envolvidos com a morte e querem manter suas almas limpas". ${ }^{17}$ A referência ao matador de aluguel nos remete de novo a Antônio das Mortes, que, como vimos, alegoricamente, também pode ser a contraparte do intelectual, a quem Euclides da Cunha acusa, entre outros setores sociais, de ser um dos responsáveis indiretos pelo massacre de Canudos. Incluindo-se nesses setores, afirma o escritor que "vivendo parasitariamente à beira do Atlântico dos princípios civilizadores elaborados na Europa, e armados pela indústria alemã — tivemos na ação um papel singular de mercenários inconscientes". ${ }^{18}$

Em Terra em transe, após a morte de um líder camponês, assassinado por fazendeiros, ligados ao governador populista, de quem o poeta era colaborador, a viúva o acusa, em prantos: "O culpado é o sinhô, doutor Paulo! O culpado é o sinhô, doutor Paulo!". ${ }^{19}$ No filme cubano, após ser absolvido da acusação de haver violado a garota que seduzira, Sergio respira aliviado, mas o ouvimos dizer, referindo-se a si, intelectual de origem burguesa, e a ela e aos seus parentes, gente humilde, que exige reparação: "Vi muito para ser inocente. Eles têm muita obscuridade na cabeça para serem culpados". ${ }^{20}$

Ao escrever sobre o fato de o "público intelectual" voltar-se para o cinema estrangeiro, "rejeitando a mediocridade com a qual possui vínculos profundos, em favor de uma qualidade importada das metrópoles, com a qual pouco tem a ver", Paulo Emílio a considera "uma aristocracia do nada, uma entidade em suma muito mais subdesenvolvida do que o cinema brasileiro que desertou". ${ }^{21}$ Daí a opção, nos anos 70, de um dos pensadores e críticos de cinema mais cultos e refinados do Brasil, de considerar positivamente filmes como os de Mazzaropi, o que levou Glauber a caracterizar a atitude de Paulo Emílio como expressão de um "esnobismo torturado". ${ }^{22}$ Este também poderia ser um traço, em sentido contrário, das posições estéticas e políticas do próprio cineasta, e uma marcante característica das personagens do poeta e do escritor em Terra em transe e Memórias do subdesenvolvimento, (auto) retratos dolorosos do artista-intelectual latinoamericano, em dois dos maiores momentos do cinema político mundial.

A não ser que se tenha caído na armadilha, não há comprazimento narcísico na contemplação da tela de um espelho que nos devolve imagens tão pouco agradáveis. Para que se fuja dessa trampa, pode ser útil compreender o processo de "identificação antipática”, de que fala Roberto Schwarz, a respeito de Os fuzis (1963), de Ruy Guerra:

Concentrando-se nos soldados, que vieram da capital a chamado, para defender um armazém, a trama força a identificação antipática, o autoconhecimento: entre os famintos e a polícia, a compaixão vai para os primeiros, mas é na segunda que estão nossos semelhantes. ${ }^{23}$

\section{(4)}

\footnotetext{
${ }^{17}$ Alea, Desnoes. Memories of underdevelopment, p.48.

${ }^{18}$ Cunha. Os sertões, p.6.

${ }^{19}$ Rocha. Roteiros do Terceyro Mundo, p.299.

${ }^{20}$ Alea, Desnoes. Memories of underdevelopment, p.91.

${ }^{21}$ Gomes. Cinema: trajetória no subdesenvolvimento, p.87.

${ }^{22}$ Rocha. Revolução do Cinema Novo, p.438.

${ }^{23}$ Schwarz. O pai de família, p.30.
} 


\section{A B STRACT}

This article is a comparative study between Glauber Rocha's Land in Anguish and Gutiérrez Alea's Memories of Underdevelopment. It aims to discuss the meanings of the poet's and writer's figures in these two films, considering their roles in Latin American cultural, social and political scenes.

\section{KEY-WORDS}

Gutiérrez Alea, Glauber Rocha, cinema, literature, Latin American culture

\section{REFERÊNCIAS BIBLIOGRÁFICAS}

Ahmad, Aijaz. In Theory: Classes, Nations, Literatures. London: Verso, 1992.

AlEA, Tomás Gutiérrez, Desnoes, Edmundo. Memories of underdevelopment. New Brunswick: Rutgers University Press, 1990.

Alea, Tomás Gutiérrez. Dialética do espectador. Trad. Itoby Correa. São Paulo: Summus, 1984.

Bernardet, Jean-Claude. Brasil em tempo de cinema. Rio de Janeiro: Paz e Terra, 1976.

Bernardet, Jean-Claude. Historiografia clássica do cinema brasileiro; metodologia e pedagogia. São Paulo: Annablume, 1995.

BurTON, Julianne. Memorias del subdesarrollo em tierras del superdesarrollo. In: FORNET, Ambrosio (org.). Alea - Una retrospectiva crítica. La Habana: Letras Cubanas, 1998.

Cunha, Euclides. Os sertões (Campanha de Canudos). Rio de Janeiro: Ediouro, [s.d.].

FERnÁNDEZ, Henry. Diacritics. In: Fornet, Ambrosio (org.). Alea - Una retrospectiva crítica. La Habana: Letras Cubanas, 1998.

Gomes, Paulo Emílio Salles. Cinema: trajetória no subdesenvolvimento. Rio de Janeiro: Paz e Terra/ Embrafilme, 1980.

Jameson, Fredric. Third-World Literature in the Era of Multinational Capitalism. Social Text. Durham, n.15, p.65-88, fall 1986.

Rocha, Glauber. Revolução do Cinema Novo. Rio de Janeiro: Alhambra/Embrafilme,1981.

Rocha, Glauber. Roteiros do Terceyro Mundo. Senna, Orlando (org.). Rio de Janeiro: Alhambra/ Embrafilme, 1985.

Schwarz, Roberto. O pai de família e outros ensaios. Rio de Janeiro: Paz e Terra, 1978. p.27-33: O cinema e Os Fuzis.

\section{REFERÊNCIAS FILMOGRÁFICAS}

O DESAFIO. Direção de Paulo César Saraceni. Rio de Janeiro, 1965, 90 min., preto-e-branco.

O dragão da maldade contra o santo Guerreiro. Direção de Glauber Rocha. Rio de Janeiro, 1969, 95 min., colorido.

Os fuzis. Direção de Ruy Guerra. Rio de Janeiro, 1963, 120/89 min., preto-e-branco.

Hiroshima, meu Amor. Direção de Alain Resnais. Paris, 1958, 91 min., preto-e-branco.

Os InCONFIDENTES. Direção de Joaquim Pedro de Andrade. Rio de Janeiro, 1972, 100 min., colorido.

Memórias do subdesenvolvimento. Direção de Tomás Gutiérrez Alea. La Habana, 1968, 97 min., preto-e-branco.

TerRa em TRANSE. Direção de Glauber Rocha. Rio de Janeiro, 1967, 115 min., preto-e-branco. 